\title{
Retirement and leisure: a longitudinal study using Swedish data
}

\author{
Linda Kridahl*
}

\section{Abstract}

This study explores engagement in leisure activities in relation to retirement among individuals aged 58-75 using Swedish longitudinal data over the 1981-2010 period. Our focus is on the relationship between leisure engagement before retirement and retirement timing, as well as on the relationship between leisure engagement before and after retirement. Engagement in leisure is measured through participation in several leisure activities which are popular in Sweden. The results indicate that leisure engagement is not associated with retirement timing when period is considered in the models. It is noteworthy that when the effect of period is excluded, but central predictors of retirement timing are included, leisure engagement is shown to be statistically significant. The results also indicate that leisure engagement patterns in retirement tend to be a continuation of preretirement leisure engagement patterns. The policy implications of these results for active ageing and health are discussed.

\section{Introduction}

Health and economic factors are the main predictors of retirement. But as health continues to improve and longevity continues to rise, other less studied predictors, such as leisure engagement, may become increasingly important. Employees may evaluate their ability to participate in leisure activities when they retire, and, depending on their assessment of the attractiveness of and their options for engaging in leisure activities, be pulled towards retirement or towards remaining in paid work (Beehr 1986; Laslett 1996; Higgs et al. 2003). Employees may expect to be able to spend more time on leisure activities when they retire (Watts 1987; Laslett 1996), but the ability to engage in leisure activities is not distributed equally

\footnotetext{
${ }^{*}$ Linda Kridahl, Demography Unit, Department of Sociology, Stockholm University, S-106 91 Stockholm, Sweden

E-mail: linda.kridahl@ sociology.su.se
} 
among older individuals (Freysinger 1999). In this study, we explore the relationship between leisure engagement and retirement timing in Sweden, as well as individuals' engagement in leisure activities before and after retirement using a unique set of longitudinal data. Improving our knowledge about the role leisure activities play in retirement timing is very useful, particularly in a country such as Sweden, in which many older employees enter retirement while still healthy, a large proportion of workers retire before age 65, the number of years spent in retirement has been rising steadily, and the share of older people (ages 60+) in the population is expected to increase dramatically (Jacobzone et al. 2000; Berleen 2003; Kinsella and $\mathrm{He}$ 2009). In addition, Sweden's rather flexible gender-neutral public pension system (Sundén 2006) and high rates of labour force participation among women (OECD 2008) make it possible to study both men's and women's motivations for retirement. In addition, investigating whether leisure activities are associated with retirement timing is a highly relevant topic in the current context, in which many countries are considering raising the retirement age, but also want to have an active and healthy older population who are engaged in various leisure activities. If, however, older individuals become more involved in leisure activities, they may want to decrease or cut short their labour force participation, which is in conflict with the goal of raising the retirement age. In addition, leisure activities in old age have been found to be beneficial for life satisfaction (Fly et al. 1981), health, and longevity (Everard et al. 2000; Lennartsson and Silverstein 2001; Agahi et al. 2011). Leisure may also prevent social isolation (Rowe and Kahns 1998), and help older people cope with the loss of family members, friends, or functions (Silverstein and Parker 2002; Janke et al. 2008). Because of the many benefits to elderly people of participation in leisure activities, leisure engagement is often promoted at a national level. Increasing the share of the older population remain who remain healthy and active, and who can therefore contribute to society and do not require care, has been cited as an important governmental goal in several countries (Taylor et al. 2004; Zaidi et al. 2013). Having additional knowledge about participation in leisure activities among the elderly would be beneficial for individuals and the public, as it could contribute to improvements in health, and thus help to lower public health care costs.

The purpose of this study is twofold. First, the importance of leisure engagement on the transition to retirement is explored. There is little existing research on this topic, either internationally or for Sweden. In most of the studies which have looked at leisure engagement, the results have been 'spillovers' from investigations on other subjects (e.g. Beehr et al. 2000; Strain et al. 2002; Janke et al. 2006). Second, we investigate how engagement in leisure activities changes shortly after retirement. Previous studies on leisure engagement have been inconclusive: some have indicated that participation in leisure activities after retirement increases, whereas others have found that it decreases or does not change (Beehr and Nielson 1995; Gauthier and Smeeding 2003; Agahi et al. 2006). In our analysis, we use country-representative longitudinal data from the Swedish Level-of-Living survey (LNU) collected between 1981 and 2010. This data set is unique in that it includes a wide range of detailed questions on leisure engagement, and thus captures to a great 
extent the diversity of leisure engagement patterns among the Swedish population. Leisure activities are defined as activities individuals engage in when they are not fulfilling paid or household obligations (Blackshaw 2010). Respondents are asked how often in their leisure time they engage in certain activities, including going to the cinema, shows, and restaurants; reading books; meeting friends and family; and engaging in political activities, study circles, hobbies, music, dancing, gardening, and church activities. The definition of engagement is based on a quantitative estimation of the frequency of a particular activity (i.e. never, sometimes, or often). The questions are nearly identical in all of the waves, which facilitates comparisons over a very long period of time. It is also possible to take a life course approach because a large proportion of the sample is a panel, and the data include many demographic, socio-economic, and individual measures. The data have been used for earlier studies of leisure engagement in Sweden, especially among elderly people (e.g. Agahi et al. 2006; Agahi et al. 2011). This study is the first to use the 2010 panel to examine leisure engagement in old age.

\subsection{The Swedish public pension system}

The Swedish gender-neutral public pension system ${ }^{1}$ has various incentives and regulations which provide workers with flexibility in deciding when they wish to leave the labour force. Although the mandatory retirement age was 65 until 2003, a large proportion of employees left the labour market earlier. ${ }^{2}$ Women were more likely than men to retire early, a phenomenon which has been attributed in part to the survivor's pension (Palme and Svensson 1999). In 2003, a new pension system was introduced in which employees were given the flexibility to retire at any point between the ages 61 and 67 . Individuals also have the option of moving to a part-time schedule (Sundén 2006). Since 2003, the average retirement age for both genders has remained stable at 64, with a slight increase after 2004 (Olsson 2011). However, variation in retirement timing is increasing, with many individuals retiring both before and after reaching age 65. Additionally, an increasing proportion of individuals combine paid work and retirement (Ministry of Social Affairs 2011).

1 Between 1960 and 2003, the public pension system was a pay-as-you-go system which included a flat-rate benefit and an income-related supplement pension, or ATP. Individuals with a low or a nonexistent ATP received supplemental benefits. Along with the pension scheme, there were occupational pensions (Palme and Svensson 1999). The pension system introduced in 2003 consists of a pay-as-yougo part and a funded part based on an income pension and a premium pension. In addition, there is an occupational pension, a private savings element, and a guaranteed pension for individuals with a low or a non-existent income. Labour income, parental leave, study benefits, military duty, and unemployment benefits are all included in the calculation of lifelong income (Sundén 2006).

2 Part-time early retirement from age 60 and disability retirement for individuals under age 65 who cannot perform gainful employment. The system also included possibilities for postponing retirement to age 70 (Palme and Svensson 1999). 


\section{Leisure in old age}

Leisure activities are generally defined as being voluntary, rewarding and enjoyable; although these activities may be connected to paid work or to household or family tasks (Blackshaw 2010). The relationship between leisure and obligations is not dichotomous or mutually exclusive. What is considered leisure is a matter of personal perception (Blackshaw 2010). In addition, the expansion of leisure activities and the reduction of paid work during the $20^{\text {th }}$ century indicate that paid work is becoming less important (Kraus 1984; Rojek 2000; Aguir and Hurst 2007). In addition, providing people with opportunities to engage in leisure activities, such as through public leisure facilities or subsidies of leisure costs, has become part of the political agenda (Kraus 1984; Olson 1993; Rojek 2010).

This study focuses on older individuals, a population group who have increased their participation in leisure activities in recent years (Nowotny 1994; Agahi and Parker 2005). Previous studies on ageing have shown that engagement in daily leisure activities has many health and social benefits (Menec 2003; Lennartsson and Silverstein 2001; Silverstein and Parker 2002; Agahi et al. 2006; Klumb and Maier 2007). Most European countries follow governmental directives to promote active ageing and to encourage older people to remain healthy, energetic and independent so they can continue to contribute to the economy and society (OECD 1998; Zaidi et al. 2013), while minimising their contribution to the public health burden (Taylor et al. 2004).

However, not everyone has the ability to engage in leisure. Although national policies create leisure opportunities (Olson 1993), levels of engagement in leisure vary considerably between individuals (Rojek 2000; Blackshaw 2003). The greatest limitations in old age are related to age, low income, and poor health (Hogas et al. 1998; Strain et al. 2002; Janke et al. 2006). Another constraint on participation in leisure activities is whether an individual has companionship when engaging in activities, and whether these activities are of a social character (Kelly 1995). The geographical area is also important, as individuals may be unable to participate in certain leisure activities because those activities are not available in their residential area (Jackson 1994). Another barrier to leisure engagement among older people is a lack of motivation (Rosenkotter et al. 2002). When we look at gender differences in leisure engagement patterns, we can see that women are more likely than men to participate in informal activities and are less likely to engage in physical leisure activities; whereas men are more likely than women to engage in formal and physical leisure activities (Bennett 1998; Bittman and Wajcman 2000). These gaps can be partly explained by the fact that, historically, women had fewer opportunities than men to engage in leisure opportunities due to economic constraints and the pressure to take on time-consuming domestic responsibilities (Rojek 2010; Blackshaw 2003). Moreover, individuals may have other obligations which are perceived as being more important than engagement in leisure, such as care responsibilities. Women are more likely than men to have care responsibilities. In many situations these duties conflict with leisure, and thus 
represent a source of strain and tension for individuals and families. However, caring can also provide people with pleasure and satisfaction (Bedim and Guinan 2009). In addition, individuals may volunteer instead of or as part of their leisure engagement (Stebbins 1996; Wilson 2000). Studies have found that people spend more time volunteering after retirement than before they leave the labour force (Hank and Erlinghagen 2009; Van den Bogaard et al. 2014).

\section{Retirement transition}

There are many factors which can influence retirement timing. Although the focus of this paper is on leisure engagement, the following section presents some of the central factors involved in a valid specification of the associations in the analyses.

National pension systems and the labour market regulate retirement behaviours (Gould 2006), but health and economic factors constitute the strongest determinants for retirement (Hayward et al. 1989; Taylor and Shore 1995; Barnes-Farrell 2003; Nordenmark and Stattin 2009). Individuals with lower income and educational levels are the most likely to have physically demanding occupations which can result in health problems, and are therefore more likely than individuals with higher income and educational levels to retire early (Hayward and Grady 1986; Hayward et al. 1989; Blekesaune and Solem 2005). However, individuals without economic resources may have to continue work to earn higher pension benefits (Henkens 1999; Barnes-Farrell 2003). It is also possible that individuals with better economic resources may postpone retirement because they are active in occupations offering economic and status rewards which they are reluctant to lose by retiring (Laslett 1996; Soidre 2005). Retirement timing is also influenced by years in the labour force. Women with long work disruptions due to childbearing may postpone retirement to earn higher pension benefits (Henretta et al. 1993). A similar situation may arise for individuals with long periods of unemployment (Beehr and Bennett 2008).

Increasing labour force participation among women has given women the right to pension benefits based on their labour market income (Johnson 2004). A general trend among married couples is for spouses to retire at or around the same time. Because the male partner in a couple is often older than the female partner, men tend to postpone retirement while women tend to retire earlier (Ho and Raymo 2009). Other family-related matters which might lead an individual to postpone retirement or to retire early include having care responsibilities for a child (Pieta and Hayward 2002; Pienta 2003), grandchild (Szinovacz and Davey 2005), an older parent (Hatch and Thompson 1992; Himes 1994), or a spouse (Szinovacz and DeViney 2000; Pienta 2003). 


\section{Framework and hypotheses}

\subsection{Leisure activities and retirement timing}

The main concept of the theory of trade-off regarding leisure is that because time spent on leisure entails a loss of potential earnings, the price of leisure is foregone earnings. If people were rational, they would enter the labour market and continue to work only for as long as the benefits from their earnings outweighed the benefits of leisure time. This choice mechanism has been widely used in economics to analyse individuals' decisions about whether to work and whether to work part time or full time (Gratton and Taylor 2004). It can be assumed that when individuals are at the threshold of retirement, they evaluate their earnings and potential retirement leisure. If the benefits of leisure engagement outweigh the option of continuing to work, people will choose to retire. An informed choice is possible because individuals have a general overview of their potential employment earnings and pension benefits (Haworth and Veal 2004).

Related to this reasoning is the push-pull perspective which is commonly presented in the retirement literature. According to this theory, employees evaluate what they consider to be of value to them, and they are either pushed or pulled towards retirement or towards continuing to work. Push and pull factors are contextually dependent, and individuals perceive them differently (Barnes-Farrell 2003). In the context of this study, the economic theory on the work-leisure tradeoff and the pull-push approach are combined, and preretirement leisure engagement is considered a motivator and a pull factor for retirement. If retirement is considered a period of life in which people have more time for leisure, then it is possible that preretirement leisure sets an individual's expectations regarding which activities he or she might want to engage in after retirement. Previous research has found that participation in leisure activities may motivate people to retire because they are familiar with the activities they might wish to engage in during retirement, and value those activities more than employment and earnings. Although the frequency of an individual's participation in particular leisure activities may not necessarily increase during retirement (Bosse and Ekerdt 1981; Agahi et al. 2006), the person's expectations regarding leisure engagement may serve as a pull towards retirement (Beehr 1986; Higgs et al. 2006). By contrast, individuals who are not active in leisure activities may not have a clear idea of how to replace paid work, and may therefore not feel pulled towards retirement (Fly et al. 1981; Henkens 1999). It is also possible that those who lack leisure skills and who do not know what to do with their leisure time may view retirement negatively, and may not want to retire (Gee and Ballie 1999). Other studies have found that the expectation of being able to participate in leisure activities does not motivate people to retire, but the lack of evidence on this issue may be attributable to the small, cross-sectional samples used in these studies (Bosse and Ekerdt 1981; Taylor and Shore 1995; Henkens 1999; Beehr et al. 2000). 
In keeping with the primary purpose of this study-namely, to investigate how engagement in leisure activities before retirement may be associated with retirement timing - an initial hypothesis is proposed: individuals who are more involved in leisure activities before retirement retire earlier than individuals who are less involved in leisure activities before retirement. Arguably, a reverse hypothesis can be suggested, because it is likely that individuals who are more engaged in certain leisure activities will postpone retirement as they may need a higher income to continue their participation. In addition, individuals with health problems may retire earlier, which may explain their low levels of leisure engagement prior to retirement. This study cannot make causal claims about the relationship between leisure and the timing of retirement, because it is not clear whether engagement in leisure activities influences retirement timing, or whether individuals foresee their retirement and change their engagement in leisure activities in the years prior to retirement.

\subsection{Preretirement leisure and postretirement leisure}

The theoretical framework for the second main goal of the study is based on three frequently applied theories in social gerontology: continuity theory, activity theory and disengagement theory. These theories provide plausible explanations of how engagement in leisure activities before retirement develops over time. According to continuity theory, most retirees continue to participate in the leisure activities in which they participated before retirement as a replacement for paid work (Atchley 1976). Critics of this theory have suggested that it is often not possible for older people to maintain their previous lifestyle due to the various constraints that accompany increasing age (Matras 1990). According to activity theory, individuals adapt to new life situations in retirement and find activities which are suitable for their life phase. Research has shown that retirees are most satisfied with their life if they are active and strive to engage in activities to replace paid labour (Harvighust 1961). The disengagement theory describes a separation process between the retiree and the social world, in which retirees do not seek out new activities, but rather engage in familiar activities, and systematically disengage from activities with increasing age (Cumming and Henry 1961). These three theories are not necessarily mutually exclusive; they can be applied together to explain the same life phase or different phases of retirement and old age (Glamser and Hayslip 1985; Howe 1988). For instance, disengagement theory can help to explain engagement in activities at ages when the natural decline in abilities begins, and continuity theory and activity theory may help to explain behavioural patterns closer to the retirement transition.

For the purposes of this study, it can be argued that if leisure activities before retirement are associated with retirement timing, then it is possible that leisure engagement before retirement preconditions leisure engagement after retirement. The findings of some studies have shown that entering retirement increases 
engagement in leisure activities, and thus support activity theory (Iwasaki and Smale 1998; Janke et al. 2006; Van den Bogaard et al. 2013). However, the results of other studies have indicated that retirement does not increase engagement in leisure activities (Bosse and Ekerdt 1981; Rosenkoetter et al. 2001; Talyor et al. 2004; Agahi et al. 2006; Berger et al. 2005). The findings of still other studies have shown that engagement in leisure activities declines with increasing age, and thus support disengagement theory (Griffin and McKenna 1999).

To meet the second main goal of this study-namely, to investigate the level of engagement in leisure activities before retirement-three hypotheses are formulated.

Continuity theory: The level of engagement in leisure activities after retirement is continuous with the level of engagement in leisure activities before retirement.

Activity theory: The level of engagement in leisure activities after retirement is higher than the level of engagement in leisure activities before retirement.

Disengagement theory: The level of engagement in leisure activities after retirement is lower than the level of engagement in leisure activities before retirement.

This study addresses changes in levels of engagement in several activity domains, but not changes in specific forms of leisure. However, changes in activity type before and after retirement are addressed by the analysis. In addition, the study examines several different leisure activities, because different leisure activities may have different relationships with the retirement transition: i.e. participation in some activities may be associated with a postponement of retirement, while participation in other activities may be associated with early retirement.

\section{Data and methods}

LNU is a panel survey which was first conducted in 1968, and was replicated in 1974, 1981, 1991, 2000, and 2010. The sample in 1968 consisted of a random sample of $1 / 1000$ of the Swedish population aged 15 to 75 (approximately 6000 individuals). As a supplement to the original panel, additional respondents are selected in each wave, and individuals who have turned 76 are excluded. For instance, the panel in 2010 consisted of individuals born in 1935-1981 who were previously interviewed at least once in previous LNUs, which corresponded to 5881 individuals. In addition, the sample was augmented with previous respondents' children who took part in LNU 2000. To make the sample representative of the Swedish population aged 15-75, two new random samples from cohorts born in 1982-1991 and immigrants born in 1935-1981 who migrated to Sweden in 2000-2009 were included. The same procedure was used for each wave. The total sample frame for LNU 2010 was 8889 individuals, of whom 61.5 per cent participated (or 72 per cent including respondents who answered a short interview). LNU 1991 had a response rate of 76.6 per cent, and LNU 1981 had a response rate 
of 82.4 per cent. ${ }^{3}$ LNU is complemented by register data and covers topics such as family, social relations, income, wealth, working conditions, health, education, housing, political life, and leisure activities (www.sofi.su.se). ${ }^{4}$

In this study, four survey years are pooled together: 1981, 1991, 2000, and 2010. The total number of individuals in all four waves is 10,466. Individuals were observed over different periods during the 1981-2010 period. The criteria for being included in this study's sample are that the individual 1) had been interviewed at least twice 2) was at least 58 years old, and had 3) not retired before age 58 . Each individual entered the sample from any wave when the criteria were fulfilled. The sample used here consisted of 2875 individuals born in the 1915-1952 period, of whom 1358 did not retire, and 1517 retired during the observation years of 1982-2010. Of these individuals, 31 per cent participated in four waves, 27 per cent participated in three waves, and 42 per cent participated in two waves. Of the total sample, 49 per cent were men, and 51 per cent were women. Of those who retired, the age at retirement varied between 58 and 75 , with a mean age of 63 . The earliest age of retirement was restricted to 58 because it is possible to retire early at age 58 through occupational pension schemes. Sensitivity analyses have been conducted with age restrictions of 55 and 60 , and the results were similar to those presented in the study. Of the sample, 13 per cent retired at ages 58-59. Observing individuals from an earlier age would increase the risk of sampling individuals who retired due to disability. The year of retirement was self-defined by the respondents. The data include no direct information on whether the transition was voluntary or forced. Swedish retirees are permitted to continue to work after retirement, although it is rare for them to do so. While the data contain no information on this phenomenon, a question about the desire to work after retirement was included in the 1981, 1991, and 2000 surveys. This may indicate whether the transition to retirement was voluntary or forced. Approximately 90 per cent of the individuals who retired in 1981-2000 said they did not wish to continue working.

\subsection{Leisure activity domains}

The range of leisure activities from LNU has been used in several studies (Samuelsson 2002), and is representative of the most popular leisure activities among the Swedish population. Some of the categories include a wide scope of activities (e.g. hobbies), whereas others are narrowly defined (e.g. reading books). The degree of physical engagement and commitment each activity entails also varies. Several of the activities are seasonally dependent (e.g. gardening) or require financial resources (e.g. going to shows). The activities are clearly gendered in

\footnotetext{
3 The response rate for LNU 1968 was 90.8 per cent, and the response rate for LNU 1974 was 85.2 per cent.

4 For a more detailed description of the data collection and sample, see (Eriksson and Åberg 1987) and (Evertsson and Magnusson 2014).
} 
practice. It is important to note that it is not always obvious which activities should be classified as leisure and which should not. Thus, the leisure activities examined in this study's setting, Sweden, may not be considered leisure activities in another setting. For instance, church activity may not be considered a leisure activity in countries with high levels of religiosity. In addition, each of these activities may have different effects on retirement timing. For instance, if the activities are of a social or a physical character, it is possible that individuals who engage in such activities will postpone retirement because they have the strength to continue paid work, and because participation in these activities add to their strength. By contrast, people who participate in certain activities may be motivated to retire early, because they find greater satisfaction in these activities than in paid work, or because the activities demand more regular participation.

The respondents answered the questions 'Do you usually perform the following as a leisure activity...' by answering 'never', 'sometimes', or 'often'. 5 A data limitation is that the ranking of participation frequency was crude, making the discrete change of frequency participation somewhat limited. A similar dilemma was detected by (Konolaan et al. 2000). However, the participation frequencies may indicate a qualitative change in activity. Furthermore, the variation in leisure activities in this study is a subjective measure. Other studies measuring participation in activities have included more detailed scales, such as hours per week (Rosenkoetter et al. 2001), or finer categories (Beehr and Nielson 1995; Nimrod 2007).

Following previous research, a component factor analysis was used to identify the structures of subgroups of leisure activities and to create activity indexes (Beehr and Nielson 1995; Griffin and McKenna 1999; Lennartsson and Silverstein 2001; Samuelsson 2002; Nimrod 2007). The analysis was conducted on reported leisure engagement before retirement. From the rotated factor matrix (Table 1), it is possible to estimate five subgroups of so-called leisure activity domains (Lennartsson and Silverstein 2001). Activities are presented in a domain if the factor loading was above 0.5 . This threshold was chosen because in previous methodological literature, 0.5 has been shown to be a good cut-off for factor loadings (Comrey and Lee 1992). The factor loadings indicate underlying structures, and it is possible for activities to load with several activities in multiple domains.

Domain 1 explained the largest variance, at 54 per cent. Four items loaded on domain 1: reading books, going to restaurants, going to the cinema and going to shows (including theatre, concerts and museums) (labelled cultural activities). The two activities which loaded on the next domain were visiting friends/relatives and friends/relatives visiting (labelled social relationships). The activities in domain 3 were political activities, study circles and hobbies (labelled political activity,

5 Church activities were measured with six possible answers: none, about once a year, a few times a year, about once a month, a few times a month, and once week or more. We coded the first two categories as never, the two middle categories as sometimes, and the two last categories as often. 
Table 1:

Rotated component loadings for 14 survey items on activities

\begin{tabular}{lrrrrr}
\hline Component & $\mathbf{1}$ & $\mathbf{2}$ & $\mathbf{3}$ & \multicolumn{1}{c}{$\mathbf{4}$} & \multicolumn{1}{c}{$\mathbf{5}$} \\
\hline Cinema & $\mathbf{0 . 7 1 8}$ & 0.071 & -0.074 & 0.261 & 0.009 \\
Theatre & $\mathbf{0 . 7 6 1}$ & 0.030 & 0.230 & 0.067 & 0.113 \\
Restaurant & $\mathbf{0 . 5 5 8}$ & 0.022 & 0.092 & 0.243 & 0.385 \\
Reading books & $\mathbf{0 . 6 2 3}$ & 0.070 & 0.133 & -0.278 & -0.386 \\
Gardening & 0.074 & 0.214 & 0.167 & 0.056 & $\mathbf{0 . 5 9 1}$ \\
Hobbies & 0.017 & 0.073 & $\mathbf{0 . 7 2 5}$ & -0.135 & 0.306 \\
Sports* & 0.404 & 0.103 & 0.050 & -0.256 & 0.143 \\
Study circle & 0.308 & -0.002 & $\mathbf{0 . 5 8 9}$ & 0.132 & 0.014 \\
Dancing & -0.037 & 0.023 & 0.046 & $\mathbf{0 . 6 7 0}$ & 0.146 \\
Music & 0.225 & 0.020 & 0.049 & $\mathbf{0 . 5 6 6}$ & -0.155 \\
Church activity & -0.135 & 0.167 & 0.294 & 0.311 & $-\mathbf{0 . 5 5 4}$ \\
Political activity & 0.018 & 0.049 & $\mathbf{0 . 5 1 6}$ & 0.082 & -0.194 \\
Visiting friends/relatives & 0.136 & $\mathbf{0 . 9 0 6}$ & 0.037 & 0.064 & 0.086 \\
Friends/relatives visiting & 0.035 & $\mathbf{0 . 9 2 6}$ & 0.065 & -0.026 & 0.020 \\
Eigenvalues & 2.728 & 1.594 & 1.215 & 1.085 & 1.012 \\
Percentage of total variance & 17.049 & 9.964 & 7.597 & 6.782 & 6.325 \\
\hline
\end{tabular}

Note: Loadings $\geq .10$

*Sports do not load with any other item.

hobbies and study circles). Domain 4 consisted of music (playing or singing) and dancing (labelled dance and music). The fifth domain consisted of two activities, gardening and church activities (labelled gardening and church activities). Engaging in sports (including a variety of exercise activities) did not load with any of the other activities and was therefore deleted from the study. Applying a lower cutoff of 0.4 would mean that sports could be added to domain 1, and applying a higher cut-off of 0.6 would mean that several domains would 'lose' activities. For instance, domain 5 would not be applicable because the loadings for the two activities in this particular domain are below 0.6. Other activity groupings were tested for the purposes of this study, such as creating domains based partly on the results of the factor analysis and partly on subjective groupings (e.g. including church activities in domain 3 and hobbies in domain 5). Other groupings did not significantly change any conclusions drawn in this study.

The five continuous indexes were standardised to a 0-8 range. The values were then categorised as follows: never (0-2), sometimes (3-5), and often (6-8). Never engaging suggests very low participation levels, but not necessarily a complete absence of participation. Additional consideration was given to individuals who often participated in only one of the activities within each activity domain. For example, individuals who often read books but did none of the other activities in the index were assigned the highest score in the index. Ignoring this condition would lead to a bias in which individuals who are very active in only one activity are 
Table 2:

Descriptive statistics of the leisure domains

\begin{tabular}{lcccc}
\hline & \% Never & \% Sometimes & \% Often & \% Total \\
\hline Cultural activities & 33.8 & 60.2 & 6.0 & 100 \\
Social relationships & 5.1 & 55.7 & 39.2 & 100 \\
Political activity, study circles and hobbies & 67.9 & 29.2 & 2.9 & 100 \\
Dance and music & 76.8 & 21.2 & 2.0 & 100 \\
Gardening and church activity & 27.7 & 38.6 & 33.7 & 100 \\
\hline
\end{tabular}

mistakenly assigned to the low or middle category. While it is possible to divide the indexes into more categories, this would cause the number of cases in each category to become quite small, which would make it more difficult to distinguish between active and non-active individuals. An alternative would be to dichotomise engagement into active/non-active, but such indicators may be too crude. It is also possible to use continuous indexes. Sensitivity analyses using OLS regressions with domains as a continuous scale indicated that there were some similarities with the analyses with categorised domains. However, using a continuous scale did not identify variation in engagement levels, which this study seeks to address. In addition, a sensitivity analysis with all of the activities included in a single index was tested, as were analyses in which each activity was treated separately. The results of the sensitivity analysis did not indicate how the different activities were associated with retirement timing or leisure engagement after retirement, and the separate analyses generated results similar to those of the models with categorised domains.

In Table 2, the frequencies of leisure engagement for the full sample are presented. ${ }^{6}$ We can see that the majority of the sample sometimes engaged in cultural activities, but that very few engaged often. Furthermore, a large proportion of the sample sometimes engaged in social relationships, and very few never engaged. It was much more common to never engage in political activities, study circles and hobbies, and dance and music. Very few respondents engaged in these activities often, and approximately one-fifth engaged sometimes. Involvement in gardening and church activities was more equally distributed; close to 40 per cent of respondents engaged sometimes.

6 Descriptive statistics distributed over 1981-2010 period can be found in Appendix A.1. 


\subsection{Method of analyses}

In the first part of the analysis, engagement in leisure activity domains before retirement is explored in relation to retirement timing using discrete-time survival analysis. The event of interest is the transition to retirement, which is recoded in discrete time because the data only contain annual information. Individuals' retirement transitions are observed during the 1981-2010 period from age 58 until they retire or turn 75 , or until the last LNU in 2010. Discrete time methods do not require the specific time of retirement because an individual's survival history is defined by a set of discrete time intervals. We apply complementary log-log functions which provide proportional hazard models and hazard ratios (Allison 2010). The leisure activity domains in this analysis are time-varying and may be measured before age 58 depending on age the individual retires, turns 75 , or last participates in the LNU.

For an evaluation of the second objective, multinomial logistic regression is used because the outcome variables have three categories (Retherford and Choe 1993). In the multinomial regression models, the leisure activity domains after retirement serve as the outcome variables, and the leisure activity domains before retirement serve as the main independent variables. Here, only individuals who retired before 2010 are included $(N=1110)$. For these particular analyses, activity domains are measured at two time points: engagement before retirement is derived from the 1981, 1991, or 2000 surveys; and engagement after retirement is derived from the 1991, 2000 , or 2010 surveys. Like the discrete-time survival analysis, the activity domains can be measured before age 58 .

The covariates are measured before retirement or in the most recent survey in which the respondent participated, depending on whether the respondent retired during the study period. The covariates are selected based on previous research and statistical evaluations during the study's process (see Appendix Table A.2 for details). A test for multicollinearity did not reveal a correlation between the covariates. The two health indexes, psychological well-being and physical mobility, are based on several self-reported answers to questions defined in the original data. Self-reported health is highly correlated with objective physical and mental health indicators (Wallace and Herzog 1995). Place of residence is defined by standardised homogeneous regions generated for distinct geographical areas in Sweden (Statistics Sweden 2003). Socio-economic status is divided into 1) manual workers, 2) non-manual workers, and 3) the self-employed. Farmers and fishermen are counted as self-employed (Statistics Sweden 1982).

In the first part of the analysis, some of the covariates can be considered confounders to both retirement and leisure engagement, particularly for socioeconomic status and the two health measures. Socio-economic status is associated with the amount of time and resources spent on leisure, and is highly associated with retirement timing. Moreover, health is a reason to both exit the labour force and continue paid work, and it may influence opportunities to engage in leisure. 


\section{Results}

Table 3 presents the results from the complementary log-log binary models (presented in the first column of Table 3) and the models which include all of the covariates separately for each activity domain, as well as a final model which includes all of the activity domains (presented in the last column of Table 3).

The results from the separate binary models for each activity domain (see first column in Table 3) indicate that there are statistically significant associations between engagement in leisure activities before retirement and the risk of retirement. The results indicate that individuals who engage in cultural activities before retirement have a higher propensity to retire than people who never engage in these activities. The results also indicate that sometimes engaging in social relationships decreases the risk of retirement. Engagement in political activities, study circles, and hobbies is positively with retirement timing. Engaging sometimes or often in dance and music is negatively associated with retirement timing. Individuals who sometimes engage in gardening and church activities retire later than those who never engage, and those who frequently engage in these activities retire earlier. Overall, the results indicate that engagement in cultural activities and frequent engagement in gardening and church activities is associated with early retirement; whereas engagement in political activities, study circles, hobbies, dance and music and modest engagement in social relationships, gardening and church activities is associated with a postponement of retirement.

When covariates are added in models 6-10, the significance of the leisure domains disappears. An exception is the dance and music category, which continues to be negatively associated with retirement risk. Stepwise models (available upon request from author) show that the period was predominantly responsible for the loss of a significant effect of activity engagement on retirement timing, which suggests that leisure activities retained the same pattern as in the binary models if period was excluded. We see the same pattern in model 11, which includes all of the leisure domains. As expected, in models 6 to 10 we also see that the strongest predictor of retirement is age, and the highest risk of retirement is at age 65. The other covariates follow the same pattern in all of the models and generally follow previous research on the predictors of retirement timing. Having a partner and having poor 
Table 3:

Hazard ratios of retirement by leisure activity domains. Complementary log-log models

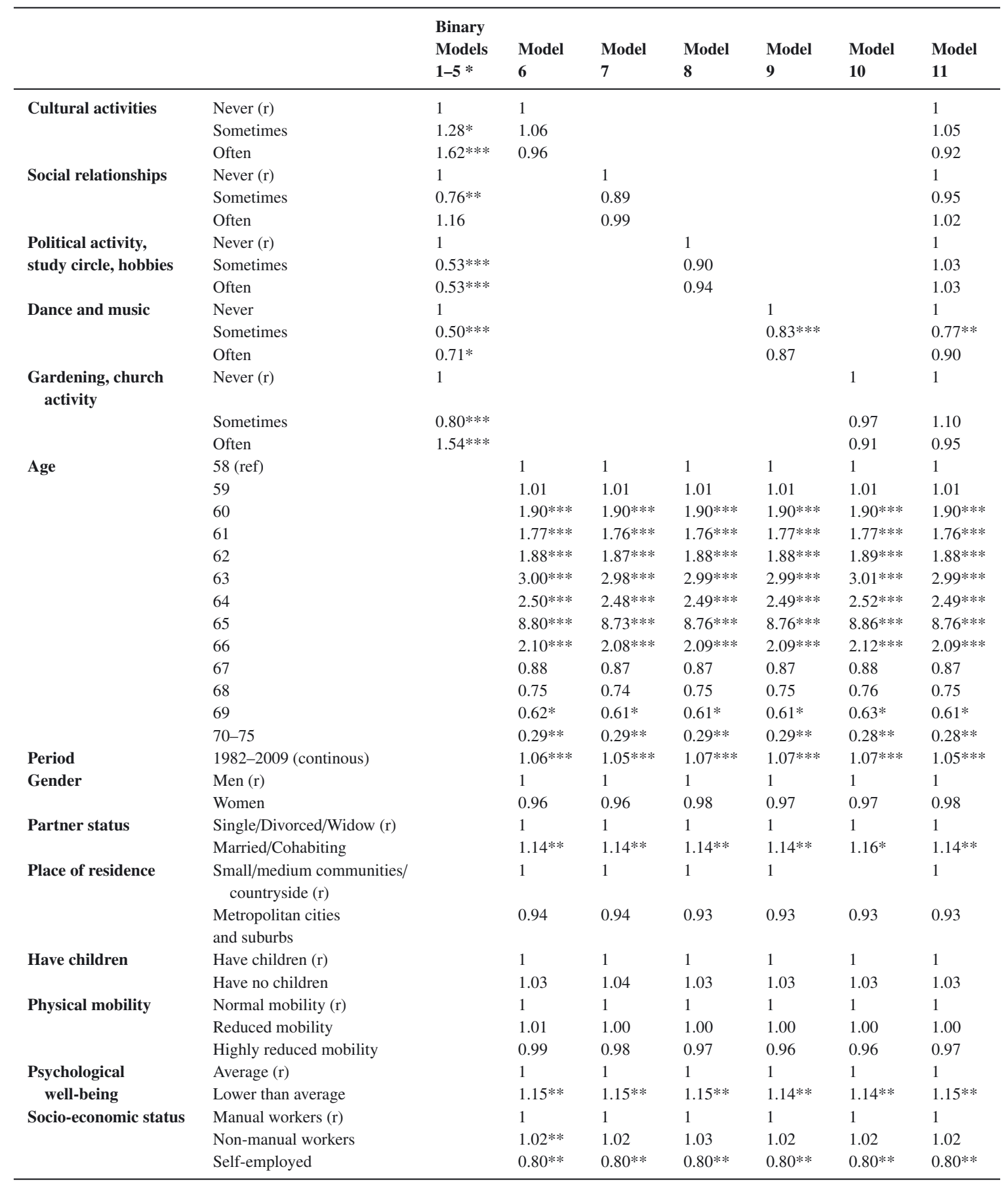

Note: $N$ of subjects $2875 ; N$ of single failures $1548 ; N$ of observations 27391.

(r) reference category, Significance levels $* p<.05 ; * * p<.01 ; * * * p<.001$.

*The binary models are run separately for each leisure activity domain, and include only the activity domains separately on retirement timing. 
psychological well-being are positively associated with retirement timing, and selfemployment is negatively associated with retirement timing. In the models stratified by gender (not presented here), the results show similar patterns. ${ }^{7}$

Next, we turn to Tables $4 \mathrm{a}$ and $4 \mathrm{~b}$ and the results from the multinomial logistic regressions in which engagement in leisure activity domains before and after retirement is explored. A likelihood-ratio test showed that the models including preretirement leisure activity domains improved the fit of the models.

The results from both the binary and the full models on engagement in cultural activities indicate that higher levels of engagement before retirement (i.e. sometimes or often) are associated with higher relative levels of engagement after retirement. Individuals who never engage in cultural activities do not tend to engage in these activities after retirement. The results further indicate that individuals who sometimes engage in cultural activities are more likely to engage in these activities often after retirement. It is also more likely for individuals who frequently participated in cultural activities before retirement to move down one engagement level (rather than to stop participating completely) than it is for individuals who never participated in these activities before retirement to move up one engagement level after retirement.

The pattern for the rest of the leisure domains is similar. The results indicate the importance of engagement or lack of engagement in the activity domains for engagement in those activities when retired. Thus, individuals largely continue their existing patterns of engagement after retirement, or make modest changes. Furthermore, in some cases the ratios are very high for the category often, which suggests that only a small number of the individuals who engaged frequently in the domain before retirement stopped engaging after retirement.

The results from the covariates indicate that women are more likely to engage in all activity domains except gardening and church activities. Having a partner is positively associated with engagement in social relationships, political activities, hobbies, study circles, and gardening and church activities. Individuals without children are less likely to engage in social relationships, dance, and music after retirement. Living in a metropolitan area is positively related with engagement in cultural activities and social relationships, but is negative for engagement in political activities, hobbies, study circles, gardening and church activities. The results also show that individuals with reduced physical mobility are less likely to engage in

\footnotetext{
7 Moreover, additional analyses have been conducted in which we estimated effect of the change in the level of engagement between two waves, 1981 and 1991, on retirement timing. Due to data restrictions, the analyses included a subgroup of individuals consisting of those who participated in three waves (1981, 1991, and 2000), with the restriction that they had to have retired between 1992 and $2000(N=516)$. The descriptive statistics indicated that the largest proportion of individuals did not change their activity level between the waves, and that more individuals had a higher level of leisure engagement in 1981, when they were younger, than they did in 1991. This pattern varied somewhat between the activity domains, but was in general rather similar. The results from the complementary $\log -\log$ models (not presented here) were not statistically significant for any of the activity domains.
} 
Table 4a:

Multinomial logistic regression. Level of engagement in leisure activities after retirement

\begin{tabular}{|c|c|c|c|c|c|c|c|c|c|c|c|c|}
\hline & \multicolumn{4}{|c|}{$\begin{array}{c}\text { Model } 1 \\
\text { Cultural activities }\end{array}$} & \multicolumn{4}{|c|}{$\begin{array}{c}\text { Model 2 } \\
\text { Social relationships }\end{array}$} & \multicolumn{4}{|c|}{$\begin{array}{c}\text { Model } 3 \\
\text { Political activity, study circle, hobbies }\end{array}$} \\
\hline & \multicolumn{2}{|c|}{$\begin{array}{l}\text { Sometims } v s \\
\quad \text { Never }\end{array}$} & \multicolumn{2}{|c|}{$\begin{array}{l}\text { Often } v s \\
\text { Never }\end{array}$} & \multicolumn{2}{|c|}{$\begin{array}{l}\text { Sometimes vs } \\
\quad \text { Never }\end{array}$} & \multicolumn{2}{|c|}{$\begin{array}{l}\text { Often } v s \\
\text { Never }\end{array}$} & \multicolumn{2}{|c|}{$\begin{array}{l}\text { Sometimes } v s \\
\quad \text { Never }\end{array}$} & \multicolumn{2}{|c|}{$\begin{array}{l}\text { Often } v s \\
\text { Never }\end{array}$} \\
\hline & Binary & Full & Binary & Full & Binary & Full & Binary & Full & Binary & Full & Binary & Full \\
\hline \multicolumn{13}{|l|}{ Cultural activities } \\
\hline Sometimes & $10.16^{* * *}$ & $7.79 * * *$ & $8.68 * * *$ & $6.09 * * *$ & & & & & & & & \\
\hline Often & $6.73^{* * * *}$ & $6.29 * * *$ & $21.1 * * *$ & $18.29 * * *$ & & & & & & & & \\
\hline \multicolumn{13}{|l|}{ Social relationships } \\
\hline Sometimes & & & & & $6.21 * * *$ & $5.38 * * *$ & $9.51 * * *$ & $8.32 * * *$ & & & & \\
\hline Often & & & & & $9.76 * * *$ & $8.48 * * *$ & $29.60 * * *$ & $24.44 * * *$ & & & & \\
\hline \multicolumn{13}{|l|}{$\begin{array}{l}\text { Political activity, study } \\
\text { circle, hobbies }\end{array}$} \\
\hline Sometimes & & & & & & & & & $3.63^{* * * *}$ & $3.28 * * *$ & $2,82 * * *$ & $2.92 * * *$ \\
\hline Often & & & & & & & & & $3.74 * * *$ & $3.27 * * *$ & $4.09 * * *$ & $4.07 * * *$ \\
\hline \multicolumn{13}{|l|}{ Age of retirement (65) } \\
\hline $58-60$ & & 1.38 & & 1.65 & & 1.62 & & 1.64 & & 0,94 & & $0.66^{*}$ \\
\hline $61-64$ & & $1.73^{* *}$ & & $2.02 * * *$ & & 1.35 & & 1.61 & & 1.17 & & 1.14 \\
\hline 66 OR older & & $1.61^{*}$ & & $2.08^{* *}$ & & $2.55 * *$ & & $3.10^{* *}$ & & 1.52 & & $1.81 * *$ \\
\hline $\begin{array}{l}\text { Year of retirement } \\
1982-2009\end{array}$ & & $1.03^{* *}$ & & $1.05 * * *$ & & 1.03 & & 1.01 & & $0.97^{*}$ & & $1.02 * *$ \\
\hline \multicolumn{13}{|l|}{ Gender (men) } \\
\hline Women & & $1.38^{*}$ & & $1.83^{* * * *}$ & & 1.35 & & $1.51^{*}$ & & 1.39 & & $1.49 * * *$ \\
\hline \multicolumn{13}{|l|}{$\begin{array}{l}\text { Partner Status (single/ } \\
\text { divorced/widow) }\end{array}$} \\
\hline \multicolumn{13}{|l|}{$\begin{array}{l}\text { Having children (have } \\
\text { children) }\end{array}$} \\
\hline Have no children & & 1.26 & & 0.99 & & 0.79 & & $0.60^{*}$ & & 1.19 & & 0.91 \\
\hline \multicolumn{13}{|l|}{$\begin{array}{l}\text { Place of residence } \\
\text { (small/medium } \\
\text { communities, } \\
\text { countryside) }\end{array}$} \\
\hline $\begin{array}{l}\text { Metropolitan cities and } \\
\text { suburbs }\end{array}$ & & $1.64 * *$ & & $2.17 * * *$ & & $1.45^{* * * *}$ & & $1.42 * * *$ & & $0.67 *$ & & 0.86 \\
\hline \multicolumn{13}{|l|}{$\begin{array}{l}\text { Physical mobility } \\
\text { (normal mobility) }\end{array}$} \\
\hline Reduced mobility & & $0.60^{* *}$ & & 0.89 & & 0.80 & & $0.50^{* *}$ & & 0.98 & & 0.92 \\
\hline Highly reduced mobility & & 0.72 & & 0.95 & & $0.34 * *$ & & $0.22 * * *$ & & 0.52 & & 0.63 \\
\hline \multicolumn{13}{|l|}{$\begin{array}{l}\text { Psychological well-being } \\
\text { (average) }\end{array}$} \\
\hline Lower than average & & 1.40 & & 1.20 & & $0.64 *$ & & $0.63^{*}$ & & $0.65^{*}$ & & 0.87 \\
\hline $\begin{array}{l}\text { Socio-economic status } \\
\text { (manual workers) }\end{array}$ & & & & & & & & & & & & \\
\hline Non-manual workers & & $2.25^{* *}$ & & $2.49 * * *$ & & 1.26 & & 1.29 & & $1.94 * * *$ & & $1.61 * * *$ \\
\hline Self-employed & & 0.77 & & 0.83 & & 1.21 & & 0.94 & & 1.66 & & 1.08 \\
\hline
\end{tabular}

Note: Reference category in parenthesis. Significance levels $* p<.05 ; * * p<.01 ; * * * p<.001 ; N=1110$.

cultural activities and social relationships, and individuals with poor psychological well-being are less likely to engage in social relationships and political activities, hobbies and study circles. In addition, non-manual workers are more likely to engage in cultural activities, political activities, hobbies and study circles, whereas self-employed are more likely to engage in dance, music, gardening and church activities. 
Table 4b:

Multinomial logistic regression. Level of engagement in leisure activities after retirement

\begin{tabular}{|c|c|c|c|c|c|c|c|c|}
\hline & \multicolumn{4}{|c|}{$\begin{array}{c}\text { Model } 4 \\
\text { Dance and music }\end{array}$} & \multicolumn{4}{|c|}{$\begin{array}{c}\text { Model 5 } \\
\text { Gardening, church activity }\end{array}$} \\
\hline & \multicolumn{2}{|c|}{$\begin{array}{l}\text { Sometimes } v s \\
\quad \text { Never }\end{array}$} & \multicolumn{2}{|c|}{$\begin{array}{l}\text { Often } v s \\
\text { Never }\end{array}$} & \multicolumn{2}{|c|}{$\begin{array}{l}\text { Sometimes } v s \\
\quad \text { Never }\end{array}$} & \multicolumn{2}{|c|}{$\begin{array}{l}\text { Often } v s \\
\text { Never }\end{array}$} \\
\hline & Binary & Full & Binary & Full & Binary & Full & Binary & Full \\
\hline Dance and music & $8.05 * * *$ & $10.95^{* * *}$ & $2.33^{* *}$ & $2.49 * * *$ & & & & \\
\hline Sometimes & $16.92 * * *$ & $14.78^{* * *} *$ & $12.32 * * *$ & $14.31 * * *$ & & & & \\
\hline \multicolumn{9}{|l|}{ Often } \\
\hline Gardening, church activity & & & & & $4.76^{* * *}$ & $4.46^{* * * *}$ & $4.66^{* * *}$ & $4.46^{* * * *}$ \\
\hline Sometimes & & & & & $3.44^{* * * *}$ & $3.17 * * *$ & $11.22 * * *$ & $3.12 * * *$ \\
\hline \multicolumn{9}{|l|}{ Often } \\
\hline \multicolumn{9}{|l|}{ Age of retirement (ref = 65) } \\
\hline $58-60$ & & $1.44 * *$ & & $0.63^{*}$ & & $0.91^{*}$ & & $0.65^{*}$ \\
\hline $61-64$ & & 1.32 & & 1.28 & & 1.03 & & 1.09 \\
\hline 66 or older & & 0.78 & & 1.35 & & 0.98 & & 1.06 \\
\hline Year of retirement $1982-2009$ & & $0.89 * * *$ & & $1.01^{*}$ & & 1.02 & & $1.04 * * *$ \\
\hline \multicolumn{9}{|l|}{ Gender $($ ref $=$ men $)$} \\
\hline Women & & 1.97 & & 1.12 & & 0.84 & & 0.95 \\
\hline \multicolumn{9}{|l|}{$\begin{array}{l}\text { Partner Status (single/divorced/ } \\
\text { widow) }\end{array}$} \\
\hline Married/Cohabiting & & 1.31 & & 1.33 & & 1.13 & & $1.42 *$ \\
\hline \multicolumn{9}{|l|}{ Having children (have children) } \\
\hline Have no children & & 1.69 & & $0.64 * *$ & & 1.19 & & 1.09 \\
\hline \multicolumn{9}{|c|}{$\begin{array}{l}\text { Place of residence (small/medium } \\
\text { communities, countryside) }\end{array}$} \\
\hline Metropolitan cities and suburbs & & 0.56 & & 1.32 & & 0.69 & & $0.70^{* *}$ \\
\hline \multicolumn{9}{|c|}{ Physical mobility (normal mobility) } \\
\hline Reduced mobility & & 0.64 & & 0.63 & & 0.67 & & 0.86 \\
\hline Highly reduced mobility & & 0.00 & & 0.97 & & 0.58 & & 0.61 \\
\hline \multicolumn{9}{|c|}{ Psychological well-being (average) } \\
\hline Lower than average & & 0.87 & & 0.96 & & 0.80 & & 0.91 \\
\hline \multicolumn{9}{|l|}{$\begin{array}{l}\text { Socio-economic status (manual } \\
\text { workers) }\end{array}$} \\
\hline Non-manual workers & & 1.28 & & $1.66^{* * *}$ & & $1.46^{*}$ & & $1.42 * *$ \\
\hline Self-employed & & $2.19 * *$ & & $0.98 *$ & & $2.24 * *$ & & 1.18 \\
\hline
\end{tabular}

Note: Reference category in parenthesis. Significance levels $* p<.05 ; * * p<.01 ; * * * p<.001 ; N=1110$.

To identify a potential disengagement process, additional analyses were conducted with the interaction between the age at retirement and the number of years between retirement and the survey year. The results did not show any consistent patterns or statistically significant results. Moreover, a robustness check using the same models analysed separately for men and women showed a pattern which was nearly identical to the one presented above, with a few exceptions. For instance, partner status was found to be statistically significant for men but not for women, which indicates that having a partner is more important for leisure engagement among retired men than among retired women. Another example is that physical mobility is important for engaging often in any of the activity domains among women, but not among men. 


\section{Discussion}

The focus of this study was the association between preretirement leisure activities and retirement timing and the association between preretirement leisure and postretirement leisure. These associations were tested with five leisure activity domains derived from four waves of the longitudinal Swedish Level-of-Living survey collected between 1981 and 2010.

In binary analyses, engagement in leisure before retirement was clearly associated with retirement timing. However, with the inclusion of other predictors, leisure engagement did not retain its significance. The predominant predictor that altered the effects for leisure activities was the period of retirement. Thus, the proposed hypothesis, individuals who are more involved in leisure activities before retirement retire earlier than individuals who are less involved in leisure activities before retirement, is not supported when we consider the period in the models. This is not surprising because changes in the pension system and the labour market can be attributed to the period. Hence, changes in the pension system or in the labour market may result in a general postponement of retirement or in early retirement. In this case, the risk of retirement decreases for the 1981-2010 period. The only association that remains is dance and music; i.e. engagement in dance and music is associated with a postponement of retirement. It is noteworthy that when the effect of period of retirement is excluded but the central predictors of retirement timing are included (such as health, income, education and marital status), the statistical significance of leisure engagement is retained; thus, the hypothesis is partly confirmed. The specific leisure activities which were related to earlier retirement were frequent engagement in cultural activities and in gardening and church activities; whereas the activities which were associated with a postponement of retirement were social relationships, political activities, study circles, hobbies, dance and music, and modest levels of engagement in gardening and church activities. It is possible that individuals who engage in cultural activities do not want to engage in activities which are time-consuming, regular, or physically or psychologically demanding. This may be because these individuals are in poor health, and prefer to engage in occasional and passive activities which are less demanding. We may assume that these individuals retire early for the same reason. It is also is possible that the individuals who engage in (costly) cultural activities are also those who can afford to retire early. Moreover, it is possible that social relationships, political activities, study circles, hobbies, church activities, dance and music are activities which are more physical, social, intellectual and regular; and that these activities demand more planning and engagement than cultural activities. Individuals who engage in these activities might be social people who have both the physical and psychological energy to interact with others and to participate in physical and intellectual activities. In turn, these activities may provide these individuals with additional physical and psychological strength. Thus, these individuals may be more likely than others to have the ability to continue to work. 
Although not all leisure activities are positively associated with retirement, the results of this study indicate that an association does exist. Previous studies have reported no statistically significant results. An important contribution of this study is that, unlike previous studies on this issue, we investigated the direct association between leisure engagement and retirement timing. From the results presented here, it seems plausible to relate leisure engagement before retirement with retirement behaviours. In such a scenario, there is a risk that political aspirations to raise the retirement age will not be efficient if individuals value leisure more than continued labour force participation. This is particularly true in cases in which leisure activities lead to earlier retirement, which creates a conflict between the need to encourage people to remain in the labour force in light of an ageing population, and the need to have a healthy older population supported by activities which encourage the postponement of retirement. A policy scenario which addresses this conflict might, for example, involve the promotion of engagement in activities which are associated with a postponement of retirement when older workers are still active in the labour force, such as through a health care allowance tied to employment which increases with increasing age. Another option is to make the cost of leisure activities tax deductible for older individuals who participate in the labour force. Such policies, which inherently cater to individuals still in paid work, would not only promote better health (as individuals who are active in their leisure time have been found to be both healthier and more satisfied with life), but may also encourage workers to postpone retirement. A suggestion for further research is to investigate why certain activities or dimensions of activities are associated with early retirement or postponed retirement, and to examine the question of whether retirement timing depends on whether leisure activities are physical, social, or intellectual.

The second association we explored was that of leisure activities before and after retirement, using a subsample which included retirees. To explain the association, we generated three hypotheses based on three common theories in social gerontology. The first hypothesis was based on continuity theory (Atchley 1976). The overall pattern supported the hypothesis, indicating that individuals tend to have the same level of engagement before and after retirement. The second hypothesis, which was based on activity theory (Harvighust 1961), implied that the level of engagement in leisure activities is likely to increase after retirement. We found that individuals were more likely to increase their engagement after retirement if they had sometimes engaged in the activity domains before retirement, possibly because they were exposed to the activities before retirement, and simply increased their engagement after retirement as a substitute for work. Thus, the findings in this study partially support the hypothesis.

The last hypothesis, which was based on disengagement theory (Cumming and Henry 1961), suggested that leisure engagement would decrease after retirement. The results do not support this hypothesis. This is likely because individuals do not disengage from activities they previously enjoyed within a short period after retirement. To indicate disengagement, we would need to find that older individuals who had retired several years previously show a pattern of decreased 
leisure engagement, and that younger individuals show continuous or increased engagement. This was not the case. The theory may better explain activity levels in later periods of life, which are not investigated in this study. It is also possible that individuals initiate a disengagement process many years before retirement by decreasing or stopping their engagement in leisure activities; hence, this process is not well captured in this analysis, and may be of greater relevance for individuals with poor health.

In sum, the results indicate that individuals tend to have the same level of engagement in leisure activities before and after retirement. Furthermore, individuals are more likely to decrease or increase their level of engagement than they are to completely stop participating in their previous activities or to start a new activity. The results clearly show that it is important that people are exposed to leisure activities before retirement if the goal is to encourage them to participate in these activities after retirement (Rosenkotter et al. 2001). This conclusion is also supported by the finding that a rather large proportion of retirees were not engaged in any leisure activity before or after retirement. This result appears to support the hypothesis based on activity theory. Moreover, there is a large risk that individuals who are not active will suffer from poor health and low levels of life satisfaction. As others have noted, it is essential to consider that the natural decline of physical and mental capabilities can be slowed or hastened depending on lifestyle (Taylor et al. 2004). This is especially important because 'non-activity' is the most stable form of activity behaviour in old age (Glamser and Hayslip 1985). Thus, it seems to be in the best interests of both individuals and society at large to encourage retirees to remain active (Rowe and Kahn 1998; Rojek 2010; Zaidi et al. 2013), in part by promoting participation in the activities individuals choose to engage in before retirement—because, as this study has shown, these activities are often carried over into retirement (see discussion by Rosenkotter et al. 2002). A broader concern is therefore to understand how governmental policies can be structured to ensure that older individuals have equal rights to engage in leisure activities (Kraus 1983; Olson 1993).

The findings of this study expand our knowledge of how engagement during labour force participation changes at retirement, and indicate that individuals do not enter retirement with the same tendency to be active. A suggestion for future research is to investigate in more detail the conditions under which individuals are likely to be active upon entering retirement. Future research should also investigate how health is affected by the level of engagement in leisure activities in relation to retirement, and should examine whether there are differences between non-active individuals before and after retirement and active individuals who continue to be active after retirement.

\section{Acknowledgements}

The author is thankful to Ann-Zofie Duvander and Ingrid Esser for their valuable comments and suggestions throughout the process of the study. Special thanks to 
the Swedish Institute for Social Research for making the Swedish Level-of-Living survey accessible.

\section{References}

Agahi, N. and M. G. Parker 2005. Are today's older people more active than their predecessors? Participation in leisure-time activities in Sweden 1992-2002. Ageing and Society 25: 925-941.

Agahi, N., K. Ahacic and M. G. Parker 2006. Continuity of leisure participation from middle age to old age. Journal of Gerontology: Social Sciences 61(6): S340-S346.

Agahi, N., M. Silverstein and M. G. Parker 2011. Late-life and earlier participation in leisure activities: The importance for survival among older persons. Activation, Adaptation and Aging 35(3): 201-222.

Aguir, M. and E. Hurst 2007. Measuring trends in leisure: The allocation of time over five decades. The Quarterly Journal of Economics 122(3): 969-1006.

Allison, P. D. 2010. Survival analysis using SAS: A practical guide. Cary, NC: SAS Institute.

Atchley, R. 1976. The sociology of retirement. New York: Schenkman Publications.

Barnes-Farrell, J. L. 2003. Beyond health and wealth: Attitudinal and other influences on retirement decision-making. In Retirement: Reasons, processes, and results, ed. G. Adams and T. Beehr, 159-187. New York: Springer.

Bedim, L. A. and D. M. Guinan 1996. "If I could just be selfish. .." Caregivers' perception of their entitlement to leisure. Leisure Sciences: An Interdisciplinary Journal 18: 227-239.

Beehr, T. A. 1986. The process of retirement: A review and recommendations for future investigation. Personnel Psychology 39: 31-55.

Beehr, A. T., S. Glazer, L. N. Nielson and S. Farmer 2000. Work and nonwork predictors of employees' retirement ages. Journal of Vocational Behavior 57: 206-225.

Beehr, T. and K. M. Bennett 2008. Unemployment and retirement. In The SAGE Handbook of organized behavior. Volume 1 - Micro approaches, ed. Barling, J. and C. L. Cooper, 217-233. London: SAGE Publications Ltd.

Beehr, T. and N. Nielson 1995. Descriptions of job characteristics and retirement activities during the transition to retirement. Journal of Organizational Behavior 16: 681-690.

Bennett, K. M. 1998. Gender and longitudinal changes in physical activities in later life. Age and Ageing 27-S3: 24-28.

Berger, U., G. Der, N. Mutrie and M. K. Hannah 2005. The impact of retirement on physical activity. Ageing and Society 25:181-195.

Berleen, G. 2003. A healthier elderly population in Sweden! National Institute of Public Health. Report 2003:41, Stockholm.

Bittman, M. and J. Wajcman 2000. The rush hour: The character of leisure time and gender equity. Social Forces 79(1): 165-189.

Blackshaw, T. 2003. Leisure life. Myth, masculinity and modernity. London: Routledge.

Blackshaw, T. 2010. Leisure. London: Routledge.

Blekesaune, M. and P. E. Solem 2005. Working conditions and early retirement: A prospective study of retirement behavior. Research on Aging 27(1): 3-30. 
Bosse, R. and D. J. Ekerdt 1981. Change in self-perception of leisure activities with retirement. The Gerontologist 21(6): 650-654.

Comrey A. L. and H. B Lee 1992. A first course in factor analysis. Hillsdale, NJ: Lawrence Erlbaum Associates.

Cumming, E. M. and W. Henry 1961. Growing old: The process of disengagement. New York: Basic Books.

Eriksson, R. and R. Åberg eds. 1987. Welfare in transition. Oxford: Clarendon Press.

Everard, K. M., W. H. Lach, B. E. Fisher and M. C. Baum 2000. Relationship of activity and social support to the functional health of older adults. Journal of Gerontology 55B(4): 208-212.

Evertsson, M. and C. Magnusson eds. 2014. Ojämlikhetens dimensioner. Stockholm: Liber.

Fly, J. W., R. G. Reinhart and R. Hamby 1981. Leisure activity and adjustment in retirement. Sociological Spectrum 1(2): 135-144.

Freysinger, V. 1999. Life span and life course perspectives on leisure. In Leisure studies: Prospects for the twenty-first century, ed. E. Jackson and T. Burton. Pennsylvania: Venture Publications.

Gauthier, A. and T. Smeeding 2003. Time use at older ages. Research on ageing 25(3): 247-274.

Gee, S. and J. Baillie 1999. Happily ever after? An exploration of retirement expectations. Educational Gerontology 25: 109-128.

Glamser, F. D. and B. Hayslip 1985. The impact of retirement on participation in leisure activities. Therapeutic Recreation Journal 19(3): 28-38.

Gould, R. 2006. Choice or chance - Late retirement in Finland. Social Policy and Society 5: $519-531$.

Gratton, C. and P. Taylor 2004. The economics of work and leisure. In Work and Leisure, ed. J. T. Haworth and A. J., Veal, 85-106. London: Routledge

Griffin, J. and K. McKenna 1999. Influences of leisure and life satisfaction of elderly people. Physical \& Occupational Therapy in Geriatrics 15(4): 1-16.

Hank, K. and M. Erlinghagen 2009. Dynamics in volunteering in older Europeans. The Gerontologist 50: 170-178.

Hatch, L. R., and A. Thompson 1992. Family responsibilities and women's retirement. In Families and retirement, ed. M. Szinovacz, D. J. Ekerdt and B. H. Vinick, 99-114. NewburyPark: Sage.

Havighurst, R. 1961. Successful aging. The Gerontologist 1(1): 8-13.

Hayward, M. D., and W. R. Grady 1986. The occupational retention and recruitment of older men: The influence of structural characteristics of work. Social Forces 64: 644-666.

Hayward, M. D., W. R. Grady, M. A. Hard and D. Sommers 1989. Occupational influences on retirement, disability, and death. Demography 26: 393-409.

Henkens, K. 1999. Retirement intensions and spousal support: A multi-actor approach. Journal of Gerontology: Social Sciences 54B(2): S63-S73.

Henretta, J., A. O'Rand. and C. Chan 1993. Gender differences in employment after spouse's retirement. Research on Aging 15(2): 148-169.

Higgs, P., G. Mein, J. Ferrie, M. Hyde and J. Nazroo 2003. Pathways to early retirement: Structure and agency in decision-making among British civil servants. Ageing and Society 
23: 761-778.

Himes, C. L. 1994. Parental caregiving by adult women: A demographic perspective. Research on Aging 16: 191-211.

Ho, J.-H. and J. M. Raymo 2009. Expectations and realization of joint retirement among dual-worker couples. Research on Aging 31(2): 153-179.

Horgas, A. L., H. U. Wilms and M. M. Baltes. 1998. Daily life in very old age: Everyday activities as expression of successful living. The Gerontologist 38: 556-568.

Howe, C. Z. 1988. Selected social gerontology theories and older adult leisure involvement: A review of the literature. The Journal of Applied Gerontology 6(4): 448-463.

Iwasaki, Y. and B. Smale 1998. Longitudinal analyses of the relationships among life transitions, chronic health problems, leisure, and psychological well-being. Leisure Sciences 20(1): 25-52.

Jackson, E. L. 1994. Geographical aspects of constraints on leisure and recreation. The Canadian Geographer / Le Gbgraphe canadien 38(2): 110-121.

Jacobzone, S. E. Cambois and J. M. Robine 2000. Is the health of older persons in OECD countries improving fast enough to compensate for population ageing? OECD Economic Studies 30(1): 149-183.

Janke, M., A. Davey and D. Kleiber 2006. Modeling change in older adult's leisure activities. Leisure Science 28: 285-303.

Johnson, R. W. 2004. Do spouses coordinate their retirement decisions? Issue in Brief No. 19. Chestnut Hill, MA: Boston College.

Kelly, J. R. 1995. Leisure and family. In Sociology of leisure: A reader, ed. C. Critcher, P. Bramham and A. Tomlison. London: Routledge.

Kinsella, K. and W. He 2009. An Aging World: 2008. U.S. Census Bureau, International Population Reports, P95/09-1. Washington DC: U.S. Government Printing Office.

Klumb, L. P. and H. Maier 2007. Daily activities and survival at older ages. Journal of Aging and Health 19(4): 594-611.

Konlaan, B. D., L. O. Bygren and S. E. Johansson 2000. Visiting the cinema, concerts, museums or art exhibitions as determinant of survival: A Swedish fourteen year cohort follow-up. Scandinavian Journal of Public Health 28: 174-178.

Kraus, R. 1984. Recreation and leisure in modern society. Glenview: Scott, Foresman and Company.

Laslett, P. 1996. A fresh map of life: the emergence of the third age. MacMillan: London.

Lennartsson, C. and M. Silverstein 2001. Does engagement with life enhance survival of elderly people in Sweden? The role of social and leisure activities. Journal of Gerontology: Social Sciences 56B (6): S335-S342.

Matras, J. 1990. Dependency, obligations, entitlements: A new sociology of aging, the life course and the elderly. Engelwood Cliffs, NJ: Prentice Hall.

Menec, V. H. 2003. The relation between everyday activities and successful aging: A 6-year longitudinal study. Journal of Gerontology 58: 74-82

Minsity of Social Affairs, Government Office of Sweden. 2011. After 65 - inte bara pension. En analys av de äldres ekonomiska situation. ISBN 978-91-38-23666-6.

Nimord, G. 2007. Retirees' leisure: activities, benefits, and their contribution to life satisfaction. Leisure Studies 26(1): 65-80. 
Nordenmark, M. and M. Stattin 2009. Psychosocial wellbeing and reasons for retirement in Sweden. Ageing and Society 29(3): 413-430.

Nowotny, H. 1994. Time. The Modern and Postmodern Experience. Cambridge: Polity Press. OECD 1998. Maintaining prosperity in an ageing society. Paris: OECD.

OECD 2008. Employment outlook. Paris: OECD.

Olson, H.-E. 1993 Leisure policy in Sweden. In Leisure policies in Europe, ed. P. Bramham, I. Henry, H. Mommaas and H. van der Poel. Wallingford: Cab International.

Olsson, H. 2011. Pensionsåldern. Statistik and Utvärdering. The Swedish Pensions Agency.

Palme, M. and I. Svensson 1999. Social security, occupational pensions, and retirement in Sweden. In Social Security and Retirement around the World, ed. J. Gruber and D. Wise, 355-402. Chicago: University of Chicago Press.

Pienta, A. M. 2003. Partners in marriage: An analysis of husbands' and wives' retirement behavior. The Journal of Applied Gerontology 22(3): 340-358.

Pienta, M. A. and M. D. Hayward 2002 Who expects to continue working after age 62 ? The retirement plans of couples. Journal of Gerontology: Social Sciences 57B(4): S199-S208.

Retherford, R. D. and K. M. Choe 1993. Statistical models for causal analysis, 151-165. New York: John Wiley and Sons.

Rojek, C. 2000. Leisure and culture. London: McMillan Press Ltd.

Rojek, C. 2010. The labour of leisure. Los Angeles: Sage Publications.

Rosenkoetter, M. M., J. M. Garris and R. A. Engdahl 2001. Postretirement use of time: implications for preretirement planning and postretirement management. Activities, Adaptation and Aging 25(3/4): 1-18.

Rowe, J. W. and R. L. Kahn 1997. Successful aging. The Gerontologist 37: 433-440.

Samuelsson, C. 2002. Att göra eller inte göra... Arbetslösas fritidsdeltagande, sökaktiviteter, anställningsmöjligheter och tidsstruktur. Doctoral Thesis. Swedish Institute for Social Research, 57. Akademitryck: Edsbruk.

Silverstein, M. and P. M. Parker 2002. Leisure activities and quality of life among the oldest old in Sweden. Research on Aging 24(5): 528-547.

Sodire, T. 2005. Retirement-age preferences of women and men aged 55-64 years in Sweden. Ageing and Society 25: 943-963.

Statistics Sweden. 2011. Regional divisions in Sweden 1 January 2011. MIS2011:1. Statistics Sweden.

Stebbins, R. A. 1996. Volunteering: A serious leisure perspective. Nonprofit and Voluntary Sector Quarterly 25(2): 211-224.

Strain, L. A., C. C. Grabusic, M. Searle and N. J. Dunn 2002. Continuing and ceasing leisure activities in later life: A longitudinal study. The Gerontologist 42(2): 217-223.

Statistics Sweden, 1982. MIS 1982:4, Socioekonomisk indelning (SEI) [Socio-economic groups] Stockholm: Statistics Sweden.

Sundén, A. 2006. The Swedish experience with pension reform. Oxford Review of Economic Policy 22(1): 133-148.

Szinovacz, M. and A. Davey 2005. Predictors of perceptions of involuntary retirement. The Gerontologist 45(1): 36-47.

Szinovacz, M. and S. DeViey 2000. Marital characteristics and retirement decisions. Research on Aging 22(5): 470-498. 
Taylor, A. H., M. T. Cable, G. Faulker, M. Hillsdon, and M. Narici 2004. Physical activity and older adults: A review of health benefits and the effectiveness of interventions. Journal of Sports Science 22(8): 703-725.

Taylor, M. A. and L. M. Shore 1995. Predictors of planned retirement age: An application of Beehr's model. Psychology and Aging 10(1): 76-83.

The Swedish Level-of-Living Survey LNU accessed on January 20, 2014 http://www.sofi.su.se/english/research/three-research-departments/lnu-level-of-living.

Van Den Bogaarden, L., K. Henkens and M. Kalmijn 2014. So now what? Effects of retirement on civic engagement. Ageing $\mathcal{F}$ Society 34: 1170-1192.

Wallace, R. B. and A. R. Herzog 1995. Overview of the health measures in the Health and Retirement Study. The Journal of Human Resources 30:S84-S107.

Watts, A. 1987. Stress in retirement and its management. Stress Medicine 3: 205-210.

Wilson, J. 2000. Volunteering. Annual Review of Sociology 26: 215-240.

Zaidi, A., K. Gasior, M. M. Hofmarcher, O. Lelkes, B. Marin, R. Rodrigues, A. Schmidt, P. Vanhuysse and E. Zolyomi 2013. Active Ageing Index 2012. Concept, methodology and final results. European Centre for Social Welfare Policy and Research, Vienna. 


\section{Appendix}

Table A.1:

Distribution of the leisure activity domains, 1981-2010 (\%)

\begin{tabular}{|c|c|c|c|c|}
\hline & 1981 & 1991 & 2000 & 2010 \\
\hline \multicolumn{5}{|c|}{ Cultural activities } \\
\hline Never & 37.3 & 33.7 & 31.1 & 27 \\
\hline Sometimes & 43.2 & 62.2 & 62.0 & 62.1 \\
\hline Often & 19.5 & 4.1 & 6.9 & 10.9 \\
\hline Total & 100 & 100 & 100 & 100 \\
\hline$N$ & 2853 & 2875 & 1741 & 1063 \\
\hline \multicolumn{5}{|c|}{ Social relationships } \\
\hline Never & 4.0 & 6.2 & 5.2 & 6.6 \\
\hline Sometimes & 47.7 & 77.3 & 49.7 & 43.4 \\
\hline Often & 48.3 & 16.5 & 45.1 & 49.6 \\
\hline Total & 100 & 100 & 100 & 100 \\
\hline$N$ & 2853 & 2875 & 1741 & 1063 \\
\hline \multicolumn{5}{|c|}{ Political activity, study circle and hobbies } \\
\hline Never & 30.9 & 36.3 & 49.7 & 50.2 \\
\hline Sometimes & 38.4 & 52.7 & 39.6 & 42.4 \\
\hline Often & 30.6 & 10.8 & 10.6 & 7.4 \\
\hline Total & 100 & 100 & 100 & 100 \\
\hline$N$ & 2853 & 2875 & 1741 & 1063 \\
\hline \multicolumn{5}{|c|}{ Dance and music } \\
\hline Never & 71.9 & 71.2 & 86.6 & 88.0 \\
\hline Sometimes & 10.1 & 27.1 & 10.1 & 10.2 \\
\hline Often & 18.0 & 1.7 & 3.3 & 1.8 \\
\hline Total & 100 & 100 & 100 & 100 \\
\hline$N$ & 2853 & 2875 & 1741 & 1063 \\
\hline \multicolumn{5}{|c|}{ Gardening, and church activity } \\
\hline Never & 31.0 & 36.3 & 26.1 & 23.5 \\
\hline Sometimes & 32.2 & 50.4 & 33.8 & 22.1 \\
\hline Often & 36.8 & 13.3 & 40.1 & 54.4 \\
\hline Total & 100 & 100 & 100 & 100 \\
\hline$N$ & 2853 & 2875 & 1741 & 1063 \\
\hline
\end{tabular}


Table A.2:

Distribution of covariates (\%)

\begin{tabular}{|c|c|c|c|c|}
\hline Covariates & & $\%$ All & $\%$ Not retired & $\%$ Retired \\
\hline \multirow[t]{13}{*}{ Age of retirement } & 58 & & & 7.3 \\
\hline & 59 & & & 6.5 \\
\hline & 60 & & & 10.8 \\
\hline & 61 & & & 8.9 \\
\hline & 62 & & & 8.5 \\
\hline & 63 & & & 11.9 \\
\hline & 64 & & & 8.9 \\
\hline & 65 & & & 24.9 \\
\hline & 66 & & & 5.7 \\
\hline & 67 & & & 2.1 \\
\hline & 68 & & & 1.4 \\
\hline & 69 & & & 0.9 \\
\hline & $70-75$ & & & 1.9 \\
\hline \multirow[t]{4}{*}{ Year of birth } & 1916-1928 & 40.4 & 68.5 & 15.4 \\
\hline & $1929-1938$ & 25.8 & 15.2 & 35.3 \\
\hline & $1939-1948$ & 23.9 & 11.8 & 34.7 \\
\hline & 1949-1952 & 10.0 & 4.5 & 14.7 \\
\hline \multirow[t]{2}{*}{ Gender } & Men & 49.5 & 47.8 & 50.9 \\
\hline & Women & 50.5 & 52.2 & 49.1 \\
\hline \multirow[t]{2}{*}{ Partner status } & Single/Divorced/Widow & 39.7 & 54.2 & 26.7 \\
\hline & Married/Cohabiting & 60.3 & 45.8 & 73.3 \\
\hline \multirow[t]{2}{*}{ Place of residence } & $\begin{array}{l}\text { Small/medium community } \\
\text { and countryside }\end{array}$ & 72.4 & 72.3 & 72.5 \\
\hline & $\begin{array}{l}\text { Sthlm/Gbg/Malmo: } \\
\text { inner-city/suburbs }\end{array}$ & 27.6 & 27.7 & 27.5 \\
\hline \multirow[t]{2}{*}{ Ever having children } & Have children & 74.8 & 65.7 & 82.9 \\
\hline & Have no childless & 25.2 & 34.3 & 17.1 \\
\hline \multirow[t]{3}{*}{ Physical mobility } & Normal mobility & 66.2 & 67.9 & 64.5 \\
\hline & Reduced mobility & 26.7 & 25.3 & 29.0 \\
\hline & Highly reduced mobility & 7.1 & 6.8 & 6.5 \\
\hline \multirow[t]{2}{*}{ Psychological well-being } & Average & 78.0 & 79.7 & 76.7 \\
\hline & Lower than average & 22.0 & 20.3 & 23.3 \\
\hline \multirow[t]{3}{*}{ Socio-economic status } & Non-manual workers & 49.5 & 38.7 & 51.2 \\
\hline & Manual workers & 40.0 & 42.4 & 39.3 \\
\hline & $\begin{array}{l}\text { Self-employed (incl. farmers, } \\
\text { fishermen) }\end{array}$ & 11.2 & 18.9 & 9.4 \\
\hline$N$ & & 2875 & 1358 & 1517 \\
\hline
\end{tabular}

